\title{
Using Canadian Primary Care Sentinel Surveillance Network data to examine depression in patients with a diagnosis of Parkinson disease: a retrospective cohort study
}

\author{
Kimberly Rose P. Singian RN MSN, Morgan Price MD PhD, Vicky Bungay RN PhD, \\ Sabrina T. Wong RN PhD
}

Abstract

Background: Parkinson disease is a complex neurodegenerative disorder, and a comorbidity of depression is common. We aimed to describe demographic and health characteristics of patients with Parkinson disease and examine sex differences in antidepressant prescriptions for those with comorbid depression using electronic medical records.

Methods: We analyzed Canadian Primary Care Sentinel Surveillance Network data for patients 18 years and older with a diagnosis of Parkinson disease who had at least 1 primary care encounter between Sep. 30, 2012, and Sep. 30, 2014. We used regression modelling to determine sex differences in antidepressant prescriptions. An advisory group of clinicians helped determine the common list of medications and interpreted the results.

Results: We identified a total of 1815 patients (54.9\% male) with Parkinson disease during the study period. The mean age of patients was 74.6 years. Most (82.0\%) lived in urban areas. Patients had a mean number of 15.5 primary care encouters over the 2 -year study period. Almost $40 \%$ of patients had a concurrent diagnosis of depression. More than half of the patients had received a depression diagnosis within 1 year of their Parkinson diagnosis. Eight out of every 10 patients had a prescription for at least 1 medication for depression, the most frequently prescribed being selective serotonin reuptake inhibitors (SSRIs). No sex differences were found in the number or type of medications.

Interpretation: Our findings support Canadian Parkinson Guidelines for Routine Screening of Comorbid Depression, but more evidence and decision-support tools are needed to examine the efficacy of antidepressants and assist clinicians in evaluating the frequent SSRI prescriptions in this population.

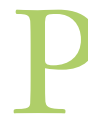
arkinson disease is the second most common neurodegenerative disorder worldwide after Alzheimer disease. ${ }^{1}$ It has an estimated prevalence rate ranging from 57 to 230 per 100000 and an incidence rate ranging from 1.5 to 26 per 100000 per year. ${ }^{2,3}$ The epidemiologic estimates increase with age and differ by sex; men have a 1.46 times higher incidence rate than women. ${ }^{2,4}$ Parkinson Society Canada reported that there are about 100000 people with the condition across Canada. ${ }^{5}$ Parkinson disease is characterized by the degeneration of dopamine-producing cells in the brain, ${ }^{1}$ resulting in motor symptoms including rest tremor, rigidity, bradykinesia and postural instability, in addition to nonmotor symptoms including depression, anxiety, cognitive decline, pain, fatigue, insomnia, constipation and urinary urgency. ${ }^{6-8}$

Many people with Parkinson disease receive their diagnosis and have their care managed in primary care. ${ }^{9}$ Available diagnostic tools are better at detecting motor symptoms than nonmotor symptoms, such as depression. ${ }^{7}$ Treatment has primarily focused on dopaminergic replacement therapy to address motor symptoms. ${ }^{10}$ Yet, past work suggests that the co-occurrence of a diagnosis of depression occurs in up to half of patients with Parkinson disease, which can exacerbate motor symptoms and negatively affect quality of life. ${ }^{11-13}$ Canadian guidelines on Parkinson disease suggest that clinicians assess for comorbid depression and tailor its management to co-existing therapy, which may include the tricyclic

Competing interests: None declared.

This article has been peer reviewed.

Correspondence to: Kimberly Rose Singian, kimberly.singian@ fraserhealth.ca

CMAJ Open 2016. DOI:10.9778/cmajo.20160052 
amitriptyline. ${ }^{12}$ Previous work using American Veteran Affairs data examined simultaneous treatment of Parkinson disease and depression. ${ }^{14,15}$ Yet, there remains limited knowledge as to how these 2 chronic conditions are treated in Canadian primary care or the patient characteristics of those with both Parkinson disease and depression.

This study aimed to describe the demographic and health characteristics of those with a diagnosis of Parkinson disease in Canadian primary care. In addition, we examined sex differences in the number and type of pharmacologic treatments for depression among those with comorbid depression. We hypothesize that there are higher rates of medication use for depression among women than among men with concurrent diagnoses of Parkinson disease and depression. Existing studies on depression treatments in general have shown that women are more likely to have higher rates of medication use for treating depression given the higher prevalence of both depression diagnosis and use of primary care among women. ${ }^{16-18}$

\section{Methods}

This retrospective cohort included a pan-Canadian sample of patients, aged 18 years and older, with a diagnosis of Parkinson diease. All patients had at least 1 primary care encounter with a participating Canadian Primary Care Sentinel Surveillance Network practice between Sept. 30, 2012, and Sep. 30, 2014.

\section{Data source}

Electronic medical record data from the pan-Canadian Primary Care Sentinel Surveillance Network were used. The network consists of 11 practice-based research networks across Canada (as of January 2016). ${ }^{19}$ Deidentified patient data (demographic characteristics [e.g., age, sex], chronic conditions [hypertension, osteoarthritis, diabetes, chronic obstructive pulmonary disease, depression, dementia, epilepsy and Parkinson disease], encounters, encounter diagnoses, billings, laboratory results, medications, allergies, physical signs [e.g., blood pressure], medical procedures, referrals, risk factors [e.g., smoking status] and vaccines) are extracted from the electronic medical records held by family physicians and nurse practitioners who voluntarily agree to be sentinels in the network. ${ }^{20}$

As of January 2016, the Canadian Primary Care Sentinel Surveillance Network contains more than 800 participating sentinels and represents about 1000000 patients. All networks received ethical approval from their institutions and Health Canada.

The Canadian Primary Care Sentinel Surveillance Network represents a similar geographic distribution to the 2010 National Physician Survey. ${ }^{21}$ A recent cross-sectional study found that the network physicians were more likely to be female, less than 45 years of age and in academic practice when compared with the 2013 National Physician Survey. ${ }^{22}$ At the time of this study, there were more than 600000 patients in network who were systematically older but reasonably similar to the age distribution of 2011 Canadian Census. $^{21,22}$

\section{Diagnoses of Parkinson disease and depression}

All case definitions for the chronic conditions were based on diagnostic code descriptions (International Statistical Classification of Diseases and Related Health Problems, 9th revision codes), free text searches within the problem list, billing and encounter diagnoses, laboratory results and medication history. ${ }^{23}$

The previously validated case definition for Parkinson disease was used and included paralysis agitans and parkinsonism. ${ }^{23}$ Tremor, Wolf-Parkinson-White syndrome and "suspected" or "possible" variants were excluded. ${ }^{23}$ The diagnosis of Parkinson disease in the Canadian Primary Care Sentinel Surveillance Network has $98.8 \%$ sensitivity, $99.0 \%$ specificity, $82.0 \%$ positive predictive value and $99.9 \%$ negative predictive value. ${ }^{23}$

The case definition for depression included episodic mood disorders, depressive disorder, bipolar, manic affective disorder, manic episodes, mild depression (not simply clinical depression); exclusions were anxiety disorders, alcohol or drug-induced mental disorders, schizophrenic disorders, delusional disorders, nonorganic psychoses, pervasive developmental disorders or other intellectual disabilities. The depression case definition has $81.1 \%$ sensitivity, $94.8 \%$ specificity, $79.6 \%$ positive predictive value and $95.2 \%$ negative predictive value. $^{23}$

\section{Data collection}

Data were obtained from the Canadian Primary Care Sentinel Surveillance Network through a data access request. We used a 2-year period because it is the recommended number of years needed to define a primary care practice population. ${ }^{24}$ We recruited an advisory group of 5 voluntary primary care physicians in British Columbia and Alberta. The advisory group helped determine the common list of medications for depression. Upon completing data analyses, key informant telephone interviews were conducted to assist with interpretation. Participants were offered Can $\$ 20$ as a token of appreciation. Interviews were recorded, summarized and synthesized. Procedures were approved by the University of British Columbia Behavioural Ethics Board. ${ }^{25}$

\section{Key variables}

Demographic characteristics included sex, current age, age at diagnosis, duration of Parkinson disease, number of encounters with a primary care provider in a 1-year and 2-year period and geographic residence. Health characteristics included body mass index (BMI), smoking status and number and type of comorbidities. In addition, we examined age at diagnosis and duration of depression. Data collected on pharmacologic treatments for depression included number and type of medications prescribed in a 2-year period. Appendix 1 (available at www.cmajopen.ca/content/4/3/E417/suppl/ DC1) shows the types of medications for depression commonly used in primary care. ${ }^{18}$ Benzodiazepines and related hypnosedatives were added because these can be prescribed for treating symptoms of depression, including insomnia and agitation. ${ }^{26}$ We used the World Health Organization's Ana- 
tomic Therapeutic Chemical index and RxFiles' comparison chart to create the list of common benzodiazepines and related hypnosedatives. ${ }^{27,28}$

\section{Data analysis}

To detect sex differences in the number and type of pharmacologic treatments for depression, a power calculation was conducted using $G^{*}$ Power ${ }^{29}$ for a medium effect size (51 patients per group [male, female]). All analyses were carried out using R Studio (version 3.1.2). Descriptive statistics included percentages, means and standard deviations to determine frequency distributions and assess heterogeneity. ${ }^{30} \mathrm{We}$ examined correlations between the following variables: age, number of comorbidities, number of encounters and the dependent variables of interest. Neither age nor number of comorbidities were significant; thus, they were excluded from the regression modelling. Inferential statistics provided a method for drawing tentative conclusions about a population from a sample. ${ }^{30} \mathrm{~A} t$ test was used to test sex differences between means and a $\chi^{2}$ test was used to compare sex differences in proportions. Poisson and logistic regression modelling were used to test sex differences in the number and type of pharmacologic treatments for depression, as rate and odds ratios (ORs), respectively, while controlling for the number of encounters with a primary care provider in a 2 -year period. The number of encounters was a covariate that used a log-2 scale to account for outliers influencing the regression models.

\section{Results}

There were a total of 1815 patients, 996 men (54.9\%) and 819 women $(45.1 \%)$, with a diagnosis of Parkinson disease. The characteristics of these patients are shown in Table 1. The mean age of the patients was 74.6 years (standard deviation [SD] 12.4). On average, patients received their diagnosis at 71.3 years of age (SD 12.6). The mean number of encounters with a primary care provider was 15.5 over 2 years. Most patients $(82.0 \%)$ lived in urban areas. The average BMI of patients was $26.7 ; 37.5 \%$ of those with a recorded BMI were overweight. About $55.3 \%$ of patients with a recorded smoking status had never smoked. Most patients with $(83.6 \%)$ also had 1 or more of the chronic conditions recorded by surveillance network. The most frequent comorbidities were hypertension (64.1\%), depression (38.1\%) and osteoarthritis (37.7\%). Men had significantly fewer diagnoses of depression and osteoarthritis than women.

\section{Demographic and health characteristics}

Among patients with comorbid depression, 51.0\% were female. Although some received a diagnosis of depression before that of Parkinson disease, about 58.1\% had a diagnosis of depression within 1 year of receiving their Parkinson diagnosis. The mean number of encounters with a primary care provider for patients with diagnoses of Parkinson disease and depression was higher than among patients with just a Parkinson disease diagnosis $(8.5$ v. 7.5 encounters in a 1 -year period). Women with a diagnosis of Parkinson and those with diagnoses of Parkinson and depression had higher mean numbers of encounters with a primary care provider than men.

Table 2 describes the prescribed pharmacologic treatments for depression in patients with diagnoses of Parkinson diseaseand depression. The average number of medications for depression in patients with both diagnoses was 1.8 (SD 1.2). Amitriptyline, suggested as the first line of treatment by the Canadian guidelines, ${ }^{12}$ was prescribed to $4.5 \%$ of patients with both diagnoses. Most of the prescribed medications for depression were selective serotonin reuptake inhibitors (SSRIs), followed by benzodiazepines and related hypnosedatives (47.2\%).

There were no significant differences for the number or type of prescribed medications for depression between men and women after controlling for the number of encounters with a primary care provider in a 2-year period (Tables 3 and 4).

\section{Interpretation}

We used primary care electronic medical record data to examine the characteristics and pharmacologic treatments of patients with a diagnosis of depression in a cohort of patients with a diagnosis of Parkinson disease. Patients with Parkinson disease represented $0.3 \%$ of the total patients in Canadian Primary Care Sentinel Surveillance Network during the study period. This prevalence is higher than the $0.2 \%$ estimate of patients with Parkinson disease in the 2010/2011 Canadian Community Health Survey. ${ }^{31}$ The mean age at diagnosis of in our cohort was older than the reported typical age of onset of 50-75 years old. ${ }^{2,4,6}$ The prevalence of comorbid depression was higher than the reported general lifetime prevalence of depression among Canadians aged 65 years and older $(11 \%-$ $20 \%) .{ }^{18}$ Our results are comparable to past work not completed in primary care, whereby depression is reported in up to $50 \%$ of patients with Parkinson disease. ${ }^{11-13}$ The sex difference in the prevalence of depression in our study is lower than in the Canadian population. ${ }^{32}$ It is possible that sex differences diminish with age, ${ }^{32}$ which may be reflective of the study's older sample of patients.

The prevalence of prescribed antidepressants is comparable to what is reported for those with a diagnosis of depression in a study using Canadian Primary Care Sentinel Surveillance Network data from 2011 to $2012 .{ }^{18}$ We did not find women with Parkinson disease to have a statistically significant difference in the number or type of prescribed medications for depression compared with men. This result is somewhat surprising given the prevalence of depression diagnosis and use of primary care appear to be higher in women. ${ }^{16-18}$ The reasons for the lack of sex differences require more research. The most frequently prescribed type of antidepressant, SSRIs, is comparable to past American Veteran Affairs studies involving patients with Parkinson disease and depression. ${ }^{14,15}$ In addition, depression treatment in the general population shows a high prescribing average $(68.0 \%)$ of SSRIs in Canadian primary care practices. ${ }^{18}$ Possible explanations for this high frequency might be the current general prescription trends and lower adverse effect profile compared with other antidepressants. ${ }^{15}$ 
Table 1: Characteristics of patients with Parkinson disease in the Canadian Primary Care Sentinel Surveillance Network

\begin{tabular}{|c|c|c|c|}
\hline Characteristic & $\begin{array}{c}\text { Men, no. }(\%)^{*} \\
n=996\end{array}$ & $\begin{array}{c}\text { Women, no. }(\%)^{*} \\
n=819\end{array}$ & $\begin{array}{c}\text { Overall, no. }(\%)^{*} \\
n=1815\end{array}$ \\
\hline Age,$\uparrow$ mean \pm SD & $74.1 \pm 11.8$ & $75.1 \pm 13.4$ & $74.6 \pm 12.4$ \\
\hline $14-50$ & $29(2.9)$ & $44(5.4)$ & $73(4.0)$ \\
\hline $51-60$ & $94(9.5)$ & $55(6.7)$ & $149(8.2)$ \\
\hline $61-70$ & $208(20.9)$ & $156(19.1)$ & $364(20.1)$ \\
\hline $71-80$ & $341(34.3)$ & $237(29.0)$ & $578(31.9)$ \\
\hline $81-90$ & $282(28.4)$ & $258(31.6)$ & $540(29.8)$ \\
\hline$>90$ & $40(4.0)$ & $67(8.2)$ & $107(5.9)$ \\
\hline Age at diagnosis of Parkinson disease, $\dagger$ mean \pm SD & $70.9 \pm 11.7$ & $71.8 \pm 12.6$ & $71.3 \pm 12.6$ \\
\hline Duration of Parkinson disease, $\mathrm{yr}, \dagger$ mean $\pm \mathrm{SD}$ & $3.3 \pm 2.8$ & $3.4 \pm 2.8$ & $3.3 \pm 2.8$ \\
\hline \multicolumn{4}{|l|}{ Encounters with a primary care provider, mean \pm SD } \\
\hline 1-year period & $7.2 \pm 9.2$ & $7.9 \pm 10.1$ & $7.5 \pm 9.6$ \\
\hline 2-year period & $14.7 \pm 16.1$ & $16.3 \pm 17.3$ & $15.5 \pm 16.7$ \\
\hline \multicolumn{4}{|l|}{ Residence type† } \\
\hline Urban & $780(81.3)$ & $653(82.3)$ & $1433(82.0)$ \\
\hline Rural & $180(18.8)$ & $135(17.1)$ & $315(18.0)$ \\
\hline Body mass index $\uparrow$, mean $\pm S D$ & $27.0 \pm 4.8$ & $26.2 \pm 5.6$ & $26.7 \pm 5.2$ \\
\hline Body mass index category & $n=483$ & $n=370$ & $n=853$ \\
\hline Normal (18-24) & $144(29.8)$ & $144(38.9)$ & $288(33.8)$ \\
\hline Underweight $(<18)$ & $1(0.2)$ & $8(2.2)$ & $9(1.1)$ \\
\hline Overweight (25-29) & $202(41.8)$ & $118(31.9)$ & $320(37.5)$ \\
\hline Obese $(\geq 30)$ & $136(28.2)$ & $100(27.0)$ & $236(27.7)$ \\
\hline Smoking status* & $n=451$ & $n=328$ & $n=779$ \\
\hline Never & $223(49.6)$ & $208(63.4)$ & $431(55.3)$ \\
\hline Current & $47(10.4)$ & $38(11.6)$ & $85(10.9)$ \\
\hline Past & $181(40.1)$ & $82(25.0)$ & $263(33.8)$ \\
\hline No. of comorbidities $\ddagger$, mean \pm SD & $1.7 \pm 1.2$ & $1.9 \pm 1.3$ & $1.8 \pm 1.3$ \\
\hline 0 & $168(16.9)$ & $130(15.9)$ & $298(16.4)$ \\
\hline 1 & $300(30.1)$ & $234(28.6)$ & $534(29.4)$ \\
\hline 2 & $281(28.2)$ & $207(25.3)$ & $488(26.9)$ \\
\hline$\geq 3$ & $247(24.8)$ & $248(30.3)$ & $495(27.3)$ \\
\hline Type of comorbidity§ & $n=828$ & $n=689$ & $n=1517$ \\
\hline Hypertension & $520(62.8)$ & $453(65.8)$ & $973(64.1)$ \\
\hline Depression $\ddagger$ & $283(34.2)$ & $295(42.8)$ & $578(38.1)$ \\
\hline Osteoarthritis $\ddagger$ & $259(31.3)$ & $313(45.4)$ & $572(37.7)$ \\
\hline Dementia & $245(29.6)$ & $194(28.2)$ & $439(29.0)$ \\
\hline Diabetes & 232 (19.6) & $162(33.7)$ & $394(26.0)$ \\
\hline COPD† & 146 (17.6) & 78 (11.3) & $224(14.8)$ \\
\hline Epilepsy & $26(3.1)$ & $28(4.1)$ & $54(3.6)$ \\
\hline \multicolumn{4}{|c|}{$\begin{array}{l}\text { Note: } \mathrm{COPD}=\text { chronic obstructive pulmonary disease, } \mathrm{SD}=\text { standard deviation. } \\
\text { *Unless otherwise specified. } \\
\text { †Missing data: age, age at diagnosis of Parkinson disease, duration of Parkinson disease and residence type had }<4.0 \% \text { missing data; body mass index was missing for } \\
53.0 \% \text { of patients; smoking status was missing for } 57.1 \% \text {. } \\
\text { †Significance by sex defined as } p<0.05 \text { using } t \text { test and } \chi^{2} \text { of independence test. } \\
\S \text { Column percentage is }>100 \% \text { because patients could have more than } 1 \text { chronic condition. }\end{array}$} \\
\hline
\end{tabular}


Table 2: Recorded medications for depression in patients with diagnoses of both Parkinson disease and depression in the Canadian Primary Care Sentinel Surveillance Network

\begin{tabular}{|c|c|c|c|}
\hline Characteristic & $\begin{array}{c}\text { Men, no. }(\%)^{*} \\
n=283\end{array}$ & $\begin{array}{c}\text { Women, no. }(\%)^{*} \\
n=295\end{array}$ & $\begin{array}{c}\text { Overall, no. (\%)* } \\
n=578\end{array}$ \\
\hline Age at diagnosis of depression, $\mathrm{yr}$, mean $\pm \mathrm{SD}$ & $71.8 \pm 11.9$ & $72.0 \pm 12.3$ & $71.9 \pm 12.1$ \\
\hline Diagnosed before Parkinson disease & $121(42.8)$ & $121(41.0)$ & $242(41.9)$ \\
\hline Diagnosed after Parkinson disease & $162(57.2)$ & $174(58.9)$ & $336(58.1)$ \\
\hline Duration of depression, $\mathrm{yr}$, mean $\pm \mathrm{SD}$ & $5.0 \pm 3.1$ & $4.8 \pm 3.2$ & $4.9 \pm 3.2$ \\
\hline \multicolumn{4}{|l|}{ Encounters with a primary care provider, mean \pm SD } \\
\hline 1-year period & $8.3 \pm 9.1$ & $8.6 \pm 8.5$ & $8.5 \pm 8.8$ \\
\hline 2-year period & $17.2 \pm 16.5$ & $17.7 \pm 15.6$ & $17.5 \pm 16.1$ \\
\hline No. of medications for depression, mean $\pm \mathrm{SD}$ & $1.7 \pm 1.2$ & $1.9 \pm 1.2$ & $1.8 \pm 1.2$ \\
\hline 0 & $44(15.5)$ & $36(12.2)$ & $80(13.8)$ \\
\hline 1 & $76(26.9)$ & $91(30.8)$ & $167(28.9)$ \\
\hline 2 & $96(33.9)$ & $82(27.8)$ & $178(30.8)$ \\
\hline$\geq 3$ & $67(23.7)$ & $86(29.2)$ & $153(26.5)$ \\
\hline \multicolumn{4}{|l|}{ Type of medication for depression } \\
\hline Selective serotonin reuptake inhibitors & $140(49.5)$ & $162(54.9)$ & $302(52.2)$ \\
\hline Benzodiazepines and related hypnosedatives & $130(45.9)$ & $143(48.5)$ & $273(47.2)$ \\
\hline Atypical antipsychotic agents & $86(30.4)$ & $97(32.9)$ & $183(31.7)$ \\
\hline Serotonin-norepinephrine reuptake inhibitors & $45(15.9)$ & $54(18.3)$ & $99(17.1)$ \\
\hline Serotonin antagonist and reuptake inhibitors & $44(15.6)$ & $31(10.5)$ & $75(13.0)$ \\
\hline Tricyclics and tetracyclics & $21(7.4)$ & $36(12.2)$ & $57(9.9)$ \\
\hline Amitriptyline† & $9(3.2)$ & $17(6.0)$ & $26(4.5)$ \\
\hline Bipolar medications & $24(8.5)$ & $30(10.2)$ & $54(9.3)$ \\
\hline Monoamine oxidase inhibitors & $5(1.8)$ & $4(1.4)$ & $9(1.6)$ \\
\hline No depression medication & $44(15.5)$ & $36(12.2)$ & (80) 13.8 \\
\hline
\end{tabular}

Table 3: Encounter-adjusted Poisson regression of the recorded number of medications for depression by sex in patients with diagnoses of Parkinson disease and depression

\begin{tabular}{|c|c|c|c|c|}
\hline \multirow[b]{2}{*}{ Dependent variable* } & \multicolumn{2}{|c|}{$\begin{array}{c}\text { Sex } \\
(\text { male reference }=1.00)\end{array}$} & \multicolumn{2}{|c|}{$\begin{array}{l}\text { No. of encounters with a } \\
\text { primary care provider }\end{array}$} \\
\hline & $\mathrm{RR}(95 \% \mathrm{Cl})$ & $p$ value & $\mathrm{RR}(95 \% \mathrm{Cl})$ & $p$ value \\
\hline No. of medications & $1.08(0.95-1.22)$ & 0.2 & $1.11(1.06-1.16)$ & $<0.001^{*}$ \\
\hline
\end{tabular}

Using an advisory group allowed us to contextualize results on data contributed by sentinels in Canadian Primary Care Sentinel Surveillance Network. The advisory group suggested more work was needed to understand the efficacy of prescribing tricyclics as the first line of treatment for depression in patients with Parkinson disease. Past work on the use of SSRIs for depressive symptoms in patients with Parkinson disease remains debatable. Previous evidence suggests that SSRIs, such as paroxetine, may magnify the motor symptoms in Parkinson disease. ${ }^{33,34}$ More recent meta-analyses ${ }^{35,36}$ and the Canadian guidelines ${ }^{12}$ suggest that tricyclics might be more effective for this population. Discrepancies found between commonly prescribed SSRIs for depression and what is recommended by the Canadian guidelines ${ }^{12}$ might be the result of different factors, 


\begin{tabular}{|c|c|c|c|c|}
\hline \multirow[b]{2}{*}{ Dependent variable } & \multicolumn{2}{|c|}{$\begin{array}{c}\text { Sex } \\
(\text { male reference }=1.00)\end{array}$} & \multicolumn{2}{|c|}{$\begin{array}{l}\text { No. of encounters with a } \\
\text { primary care provider }\end{array}$} \\
\hline & OR $(95 \% \mathrm{Cl})$ & $p$ value & OR $(95 \% \mathrm{Cl})$ & $p$ value \\
\hline Selective serotonin reuptake inhibitors & $1.25(0.90-1.73)$ & 0.2 & $1.22(1.08-1.39)$ & $<0.01^{*}$ \\
\hline Benzodiazepines and related hypnosedative & $1.11(0.80-1.54)$ & 0.5 & $1.25(1.10-1.42)$ & $<0.001^{*}$ \\
\hline Atypical and antipsychotic agents & $1.12(0.79-1.59)$ & 0.5 & $1.10(0.96-1.25)$ & 0.2 \\
\hline Serotonin-norephinephrine reuptake inhibitors & $1.18(0.77-1.83)$ & 0.4 & $1.06(0.90-1.25)$ & 0.5 \\
\hline Serotonin antagonist and reuptake inhibitors & $0.64(0.39-1.04)$ & 0.07 & $1.14(0.94-1.38)$ & 0.2 \\
\hline Tricyclics and tetracyclics & $1.73(0.99-3.10)$ & 0.06 & $1.32(1.07-1.67)$ & $0.01^{*}$ \\
\hline Bipolar medications & $1.22(0.69-2.16)$ & 0.5 & $1.15(0.93-1.43)$ & 0.2 \\
\hline Monoamine oxidase inhibitors & $0.76(0.19-2.90)$ & 0.7 & $1.23(0.75-2.14)$ & 0.4 \\
\hline \multicolumn{5}{|c|}{$\begin{array}{l}\text { Note: } \mathrm{Cl}=\text { confidence intervals, } \mathrm{OR}=\text { odds ratio. } \\
\text { *Significance defined as } p<0.05 \text {. } \\
\text { Gender served as the main independent variable and the number of encounters with a primary care provider in a 2-year period served as a covariate using a log-2 scale in } \\
\text { the regression model. }\end{array}$} \\
\hline
\end{tabular}

including low baseline knowledge among providers regarding management of motor and nonmotor symptoms of Parkinson disease, ${ }^{9,45}$ current prescription trends for depression ${ }^{15}$ and insufficient evidence on the efficacy of medications for patients with comorbid depression. ${ }^{12,35,36}$ Increased practice support and resources could promote routine and comprehensive assessment of comorbidities and medications in this population. Clinicians are required to deliver individualized care but also carry out guideline-based care for multiple segments of the practice population. Nurses, pharmacists, and neurologists are valuable resources who could work more closely together to increase the quality of primary care delivered to patients with Parkinson disease. Longitudinal research could examine polypharmacy, medication dosages and durations, and nonpharmacologic treatments (e.g., referrals) when treating depressive symptoms in patients with Parkinson disease. The high prescription rate of benzodiazepines and related hypnosedatives deserves consideration because large-scale studies report that these medications continue to be frequently prescribed despite a twofold risk for falls and hip fractures among older patients. ${ }^{37-39}$

Our sample had a higher number of encounters with a primary care provider than the average visit rate of 3-5 visits per year. ${ }^{40}$ Patients with a diagnosis of Parkinson disease may need closer monitoring by primary care clinicians. A recent systematic review ${ }^{41}$ suggests that patients with concurrent diagnoses of Parkinson disease and hypertension had further decline in cognitive function beyond the deficits caused by Parkinson alone, which may explain the need for a higher number of encounters. More work is needed to understand what appropriate visit rates ought to be for different population segments within each practice.

\section{Limitations}

Findings were limited to patients with a diagnosis of Parkinson disease in the Canadian Primary Care Sentinel Surveil- lance Network within a 2-year period. Our results may not be representative of all primary care clinicians in Canada. Recent work suggests that surveillance network clinicians are younger and practice more often in an academic centre. ${ }^{22}$ As with any data source, electronic medical records are prone to error in the accurate recording of activities and diagnoses. ${ }^{42,43}$ Our confidence in the quality of the coding comes from having 10 data managers working with the clinician network directors to clean the data using established algorithms. It is possible that there could be misclassification of diagnosis type for Parkinson disease and depression owing to variation in the level of certainty between diagnoses made by neurologists and primary care physicians. Only a subset of electronic medical record data was available through the surveillance network; the recruitment of a large sample or sufficient number of patients with a diagnosis of Parkinson disease for a quantitative study might be difficult to obtain because the prevalence of the disease itself is not as common compared with other chronic diseases, such as hypertension. ${ }^{42}$ Furthermore, the existence of the Canadian Primary Care Sentinel Surveillance Network allows examination of other chronic diseases, including a recent study on dementia. ${ }^{44}$ Each surveillance network case definition refers to lifetime prevalence of only 8 chronic diseases. ${ }^{23}$ Finally, we made assumptions as to our list of medications that would be prescribed for depressive symptoms.

\section{Conclusion}

This study provides a description of the characteristics of patients with Parkinson disease and the pharmacologic treatments for depression among those with comorbid depression in Canadian primary care. Depression remains a common comorbidity, which is mostly treated by SSRIs despite guideline recommendations. Our findings highlight the need for more resources and decision-making tools to guide primary care providers in treating comorbid depression. 


\section{References}

1. Lix LM, Hobson DE, Azimaee M, et al. Socioeconomic variations in the prevalence and incidence of Parkinson's disease: a population-based analysis. 7 Epidemiol Community Health 2010;64:335-40.

2. Muangpaisan W, Mathews A, Hori H, et al. A systematic review of the worldwide prevalence and incidence of Parkinson's disease. 7 Med Assoc Thai 2011;94:749-55

3. Twelves D, Perkins KSM, Counsell C. Systematic review of incidence studies of Parkinson's disease. Mov Disord 2003;18:19-31.

4. Taylor KSM, Cook JA, Counsell CE. Heterogeneity in male to female risk for Parkinson's disease. 7 Neurol Neurosurg Psychiatry 2007;78:905-6.

5. Frequently asked questions. Toronto: Parkinson Society Canada; 2014. Available:www.parkinson.bc.ca/FAQ (accessed 2015 Aug. 27).

6. Moore KA, Seeney F. Biopsychosocial predictors of depressive mood in people with Parkinson's disease. Behav Med 2007;33:29-37.

7. Alves G, Forsaa EB, Pedersen KF, et al. Epidemiology of Parkinson's disease. 7 Neurol 2008;255:18-32

8. Shearer J, Green C, Counsell CE, et al. The impact of motor and non-motor symptoms on health state values in newly diagnosed idiopathic Parkinson's disease. 7 Neurol 2012;259:462-8.

9. Swarztrauber K, Graf E. Nonphysicians' and physicians knowledge and care preferences for Parkinson's disease. Mov Disord 2007;22:704-7.

10. Singer C. Managing the patient with newly diagnosed Parkinson disease. Cleve Clin 7 Med 2012;79(Suppl 2):S3-7.

11. Hermanns M, Deal B, Haas B. Biopsychosocial and spiritual aspects of Parkinson disease: an integrative review. 7 Neurosci Nurs 2012;44:194-205.

12. Canadian guidelines on Parkinson's disease. Toronto: Parkinson Society Canada; 2012. Available: www.parkinsonclinicalguidelines.ca/sites/default/files/PD Guidelines_2012.pdf(accessed 2015 Aug. 27)

13. Jones CA, Pohar SL, Patten SB. Major depression and health-related quality of life in Parkinson's disease. Gen Hosp Psychiatry 2009;31:334-40.

14. Troeung L, Egan SJ, Gasson N. A meta-analysis of randomised placebocontrolled treatment trials for depression and anxiety in Parkinson's disease. PLoS One 2013;8:e79510.

15. Chen P, Kales HC, Weintraub D, et al. Antidepressant treatment of veterans with Parkinson's disease and depression: analysis of a national sample. 7 Geriatr Psychiatry Neurol 2007;20:161-5.

16. Hinton L, Zweifach M, Tang L, et al. Gender disparities in the treatment of late-life depression: qualitative and quantitative findings from the IMPACT trial. Am 7 Geriatr Psychiatry 2006;14:884-92.

17. Unützer J, Katon W, Callahan CM, et al. Depression treatment in a sample of 1801 depressed older adults in primary care. 7 Am Geriatr Soc 2003; 51:505-14.

18. Wong ST, Manca D, Barber D, et al. The diagnosis of depression and its treatment in Canadian primary care practices: an epidemiological study. CMA7 Open 2014;2:E337-42.

19. Sentinels: potential sentinels. Kingston (Ont.): Canadian Primary Care Sentinel Surveillance Network; 2014. Available: http://cpcssn.ca/sentinel/potential -sentinels/ (accessed 2015 Aug. 27).

20. CPCSSN data for research: the art of the possible presentation. Kingston (Ont.): Canadian Primary Care Sentinel Surveillance Network; 2012. Available: http:// cpcssn.ca/research-resources/cpcssn-data-for-research/ (accessed 2015 Aug. 27)

21. Williamson T, Lambert-Lanning A, Martin K, et al. Primary health care intelligence: 2013 progress report of the Canadian Primary Care Sentinel Surveillance Network (CPCSSN). Kingston (Ont.): 2013. Available: http://cpcssn .ca/wp-content/uploads/2014/04/CPCSSN_2012_13_reportEN.pdf (accessed 2015 Aug. 27).

22. Queenan JA, Williamson T, Khan S, et al. Representativeness of patients and providers in the Canadian Primary Care Sentinel Surveillance Network: a cross-sectional study. CMA7 Open 2016;4:E28-32.

23. Williamson T, Green ME, Birtwhistle R, et al. Validating the 8 CPCSSN case definitions for chronic disease surveillance in a primary care database of electronic health records. Ann Fam Med 2014;12:367-72.

24. Menec V, Black C, Roos NP, et al. Defining practice populations for primary care: methods and issues. Winnipeg: Manitoba Centre for Health Policy and Evaluation, Department of Community Health Sciences, Faculty of Medicine, University of Manitoba; 2000.

25. UBC Behavioural Research Ethics Board. Guidance notes on behavioural applications: new behavioural application form. Vancouver: UBC Behavioural Research Ethics Board; 2012. Available: https://ethics.research.ubc.ca/sites/ore. ubc.ca/files/documents/Draft_Behavioural_Application_for_website.pdf (accessed 2016 July 26)

26. McMillan JM, Aitken E, Holroyd-Leduc JM. Management of insomnia and longterm use of sedative-hypnotic drugs in older patients. CMA7 2013;185:1499-505.
27. ATC/DDD index 2016. Oslo (Norway): WHO Collaborating Centre for Drug Statistics Methodology; 2016. Available: www.whocc.no/atc ddd index/ (accessed 2016 July 19).

28. Jensen B. Benzodiazepines (BZ): comparison chart; 2015. Available: www.RxFiles .ca (accessed 2015 July 15). Login required to access content.

29. Faul F, Erdfelder E, Buchner A, et al. Statistical power analyses using $\mathrm{G}^{*}$ Power 3.1: tests for correlation and regression analyses. Behav Res Methods 2009;41:1149-60.

30. Polit DF, Beck CT. Nursing research: generating and assessing evidence for nursing practice. 9th ed. Philadelphia: Lippincott, Williams \& Wilkins; 2012.

31. Wong SL, Gilmour H, Ramage-Morin PL. Parkinson's disease: prevalence, diagnosis and impact. Ottawa: Statistics Canada [Health Reports]; 2014 Nov. 9. Cat no 82-003-X. Available: www.statcan.gc.ca/pub/82-003-x/2014011/ article/14112-eng.pdf (accessed 2015 Aug. 27).

32. Patten SB, Wang JL, Williams JVA, et al. Descriptive epidemiology of major depression in Canada. Can 7 Psychiatry 2006;51:84-90.

33. Ceravolo R, Nuti A, Piccinni A, et al. Paroxetine in Parkinson's disease: effects on motor and depressive symptoms. Neurology 2000;55:1216-8.

34. Jiménez-Jiménez FJ, Tejeiro J, Martínez-Junquera G, et al. Parkinsonism exacerbated by paroxetine. Neurology 1994;44:2406

35. Liu J, Dong J, Wang L, et al. Comparative efficacy and acceptability of antidepressants in Parkinson's disease: a network meta-analysis. PLoS One 2013;8:e76651.

36. Rocha FL, Murad MG, Stumpf BP, et al. Antidepressants for depression in Parkinson's disease: systematic review and meta-analysis. 7 Psychopharmaco 2013;27:417-23

37. Allain H, Bentué-Ferrer D, Polard E, et al. Postural instability and consequent falls and hip fractures associated with use of hypnotics in the elderly: a comparative review. Drugs Aging 2005;22:749-65.

38. McMillan JM, Aitken E, Holroyd-Leduc JM. Management of insomnia and long-term use of sedative-hypnotic drugs in older patients. CMAF 2013;185:1499-505

39. Simon GE, Ludman EJ. Outcome of new benzodiazepine prescriptions to older adults in primary care. Gen Hosp Psychiatry 2006;28:374-8.

40. Murray M, Davies M, Boushon B. Panel size: How many patients can one doctor manage? Fam Pract Manag 2007;14:44-51.

41. Carey A, Julian R, Kristeller K, et al. The cardiovascular and cerebrovascular effects on cognition in persons with Parkinson's disease: a systematic review of the literature. Adv Parkinson Dis 2015;4:28-42.

42. Muller S. Electronic medical records: the way forward for primary care research? Fam Pract 2014;31:127-9.

43. Holroyd-Leduc JM, Lorenzetti D, Straus SE, et al. The impact of the electronic medical record on structure, process, and outcomes within primary care: a systematic review of the evidence. 7 Am Med Inform Assoc 2011; 18:732-7.

44. Drummond N, Birtwhistle R, Williamson T, et al. Prevalence and management of dementia in primary care practices with electronic medical records: a report from the Canadian Primary Care Sentinel Surveillance Network. CMA7 Open 2016;4:E177-84.

45. Thompson MR, Stone RF, Ochs VD, et al. Primary health care providers' knowledge gaps on Parkinson's disease. Educ Gerontol 2013;39:856-62.

Affiliations: School of Nursing (Singian, Bungay, Wong), Department of Family Practice (Price, Wong) and Centre for Health Services and Policy Research (Wong), University of British Columbia, Vancouver, BC.

Contributors: This retrospective cohort study is original, unpublished, and conducted by the principal investigator, Kimberly Rose Pineda Singian. Morgan Price, Victoria Bungay and Sabrina Wong served as coauthors and contributed substantially to the conception, design, analysis,and interpretation of data. The coauthors also provided critical feedback throughout the stages of the study, including the multiples drafts of all sections. All of the authors gave final approval of the version to be published and agreed to act as guarantors of the work.

Acknowledgement: This study was funded through the University of British Columbia School of Nursing's Helen Shore Nursing Endowment Fund. The authors thank David Parker for his assistance in using the data.

Supplemental information: For reviewer comments and the original submission of this manuscript, please see www.cmajopen.ca/content/4/3/ E417/suppl/DC1 